

\title{
El neoextractivismo y el neodesarrollismo en los contextos latinoamericano y colombiano
}

\author{
Por Freddy Díaz*
}

Resumen: el presente artículo analiza la relación que existe entre en el desarrollo convencional impulsado por los gobiernos latinoamericanos de derecha y el extractivismo convencional como su base económica fundamental, y las diferencias que presenta ese modelo con el neoextractivismo como modelo económico impulsado por gobiernos progresistas, base primordial para los programas de inversión social que buscan el mejoramiento de las condiciones socioeconómicas de sus países.

Palabras clave: neoextractivismo, neodesarrollismo, conflictos.

\section{Neo-extractivism and neo-developmentism in Latin American and Colombian contexts}

Abstract: This article analyzes the relationship between conventional development promoted by right-wing Latin American governments and conventional extractivism as its fundamental economic base, and the differences that this model presents with neo-extractivism as an economic model promoted by progressive governments, a fundamental basis for social investment programs that seek to improve the socio-economic conditions of their countries.

Keywords: neo-extractivism, neo-developmentalism, conflicts.

* De formación ambiental, egresado de la Universidad Distrital, hace parte del Instituto Nacional Sindical. Hace parte de la Secretaría de formación del Coordinador Nacional Agrario y es militante del Congreso de los Pueblos. Correo electrónico: freddydiazga@gmail.com. 
Cómo citar este artículo: Díaz, Fredy (2017). El neoextractivismo y el neodesarrollismo en los contextos latinoamericano y colombiano. Revista Controversia, 208, 57-98.

Fecha de recepción: 29 de febrero del 2017.

Fecha de aprobación: 8 de mayo del 2017.

\section{Apartado metodológico}

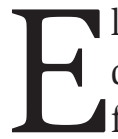

l presente texto fue desarrollado con una metodología de estudio de caso con diferentes unidades de observación; la información fue recolectada de fuentes secundarias, en su mayor parte oficiales y en menor medida informes de organizaciones.

Como se verá, los indicadores seleccionados para cada unidad de observación no provienen de la misma fuente dado que en ninguna de ellas se encontraban completos todos los datos de los años seleccionados, por cuanto fue necesario recurrir a otras fuentes para complementar la información requerida en el texto; aunque es claro que puede haber diferencias en los métodos de levantamiento de información en cada fuente, reconociendo esta limitación, se buscó ubicar datos que permitieran dar cuenta de las realidades que se quieren mostrar.

\section{Un rápido contexto}

El presente texto busca mostrar las diferencias que existen entre concepciones de desarrollo, formas de gobierno y lógicas en la apropiación de bienes comunes, y las repercusiones que todo esto tiene sobre diferentes aspectos de la vida. El texto se dividirá en dos partes: la primera se centrará en países con lógicas neoliberales y de desarrollo clásico ${ }^{1}$, la segunda tratará a los países progresistas y sus lógicas de desarrollo.

1 Las raíces históricas del desarrollo se encuentran en los grandes reacomodos políticos que ocurrieron a nivel mundial al final de la Segunda Guerra Mundial. Las nociones de "subdesarrollo" y "Tercer Mundo" aparecieron en este momento corno parte de un proceso, a través del cual el Occidente buscaba redefinirse a sí mismo y 
El boom minero-extractivo en el mundo comenzó hacia los años noventa del siglo pasado, a lo cual América Latina no fue ajena, pues desde hace siglos se le ha impuesto el papel de proveedor de materias primas; en Colombia, aunque la primera ola de extracción a gran escala se dio en el gobierno Gaviria, justo cuando el neoliberalismo entró al país, fue desde el primer gobierno Uribe donde se abrió la puerta a la inversión extranjera de gran magnitud para la extracción de bienes naturales, dinámica que continuó profundizándose durante los gobiernos Santos, aumentando todas las facilidades ambientales, políticas, fiscales y laborales.

Pero, ¿qué se entiende por extractivismo? El extractivismo es una modalidad de acumulación que comenzó a fraguarse masivamente hace quinientos años. Con la conquista y la colonización de América, África y Asia empezó a estructurarse la economía mundial al sistema capitalista. Esta modalidad de acumulación extractivista estuvo determinada desde entonces por las demandas de los centros metropolitanos del capitalismo naciente. Unas regiones fueron especializadas en la extracción y producción de materias primas, es decir, de bienes primarios, mientras que otras asumieron el papel de productoras de manufacturas. Las primeras exportan naturaleza, las segundas la importan. Para intentar una definición comprensible utilizaremos el término extractivismo cuando nos refiramos a aquellas actividades que remueven grandes volúmenes de recursos naturales que no son procesados (o que lo son limitadamente), sobre todo para la exportación. El extractivismo no se limita a

en relación con el resto del mundo, pero especialmente en relación con las nuevas potencias del Oriente. Parte de este proceso fue también la necesidad de extender la civilización industrial al mundo hasta entonces no industrializado. Por lo tanto, las nociones de desarrollo y Tercer Mundo están estrechamente ligadas en sus orígenes a las de Guerra Fría y modernización. El objetivo de las naciones que se embarcaron en la tarea del desarrollo después de la guerra fue invariablemente el mismo: la creación de un tipo de sociedad equipada con los factores materiales e institucionales requeridos para alcanzar rápidamente las formas de vida creadas por la civilización industrial. De esta forma, el “desarrollo" se convirtió en la estrategia magna para realizar los designios de la civilización industrial y al mismo tiempo adelantar en forma relativamente inocua la confrontación entre Oriente y Occidente. 
los minerales o al petróleo, hay también extractivismo agrario, forestal e inclusive pesquero (Acosta, 2012). Esta definición hay que saberla matizar, y a cada matiz es necesario hacerle algunas aclaraciones.

\section{Extractivismo y desarrollismo clásico}

Esta clase de actividad debe entenderse como un macrosistema (Pulido, 2015)², básicamente porque en él convergen los sistemas socioambiental, económico-fiscal y político-institucional. Los impactos que sufren estos sistemas son característicos de las industrias y las economías extractivas, y se presentan de manera similar en todos los países latinoamericanos con enclaves extractivos, salvo algunas diferencias que dependen del régimen político que esté en el poder.

Países como Perú, México y Colombia, con gobiernos abiertamente de derecha y neoliberales, han incentivado cambios que responden a "recomendaciones" hechas por organismos multilaterales como el Fondo Monetario Internacional -FMI - y el Banco Mundial - BM-, entre las que se destacan las impulsadas por este último en el ámbito minero en los años noventa, conocidas como A Mining Strategy for Latin America and the Caribbean, de 1993, en donde plantean, entre otras cosas, liberación estatal de la tierra para su explotación y que los inversionistas tengan asegurado el acceso a esta, de preferencia a bajos costos.

Allí también se tratan temas fiscales: el BM “recomienda” que se permita la repatriación de ganancias hacia los países de origen de las empresas extractivas, además de que los inversores tengan seguridad respecto a que los impuestos no cambiarán mucho durante el proyecto, es decir, que no aumentarán, y que no se cobren regalías, y si se cobran que sean bajas, además de que exista un mecanismo para devolver el IVA sobre las compras.

2 Este autor considera a la minería como un macrosistema, pero ya que las actividades extractivas son similares, al igual que sus dinámicas, en el presente texto se considera que el extractivismo también es un macrosistema. 
Basados en estas directrices, y aprovechado la riqueza natural que hay en sus territorios, estos países buscan apalancar el crecimiento económico, fundamentalmente anclando su economía al mercado mundial de commodities y al mercado especulativo, esto en busca de captar inversión extranjera directa —IED—, básicamente, desregulando la legislación nacional, lógica que provoca la concentración de riqueza y, además de esto, acumulación de poder político, lo que en conjunto ha logrado arrodillar al Estado en favor de las empresas extractivas.

En estos países, el modelo económico se fundamenta en crecer lo máximo posible, casi de forma ilimitada, mientras se pueda hacerlo, sin tener en cuenta las externalidades negativas, como los impactos socio-ambientales negativos o los desequilibrios político-económicos que estos produzcan.

Mientras los gobiernos de turno se concentran en elogiar los supuestos beneficios que produce la IED — como la generación de empleo, inversión social, aumento de la productividad, transferencia de conocimiento y de tecnología-, además de mostrarla como un motor de desarrollo, otra es la realidad.

Primero, es necesario entender como se ha comportado la IED en general y hacer un énfasis especial en la que se ha hecho para la extracción de bienes naturales.

Tabla 1. IED (cifras en millones de dólares)

\begin{tabular}{|l|c|c|c|c|c|c|c|c|}
\multicolumn{1}{c|}{ País } & $\mathbf{2 0 0 8}$ & $\mathbf{2 0 0 9}$ & $\mathbf{2 0 1 0}$ & $\mathbf{2 0 1 1}$ & $\mathbf{2 0 1 2}$ & $\mathbf{2 0 1 3}$ & $\mathbf{2 0 1 4}$ & $\mathbf{2 0 1 5}$ \\
\hline Colombia & 10565 & 8035 & 6430 & 14648 & 15039 & 16199 & 16054 & $11446^{*}$ \\
México & 28574 & 17644 & 25962 & 23560 & 18998 & 44627 & 22795 & $21005^{* *}$ \\
\hline Perú & 6924 & 6431 & 8455 & 7665 & 11918 & 9298 & 7607 & $7817,1^{* * *}$
\end{tabular}

Fuente: CEPAL.

* ProColombia, datos de la balanza cambiaria del Banco de la República, 2016.

** Banco Santander México.

*** Proinversión, 2016. 


\section{Gráfica 1. IED (cifras en millones de dólares)}

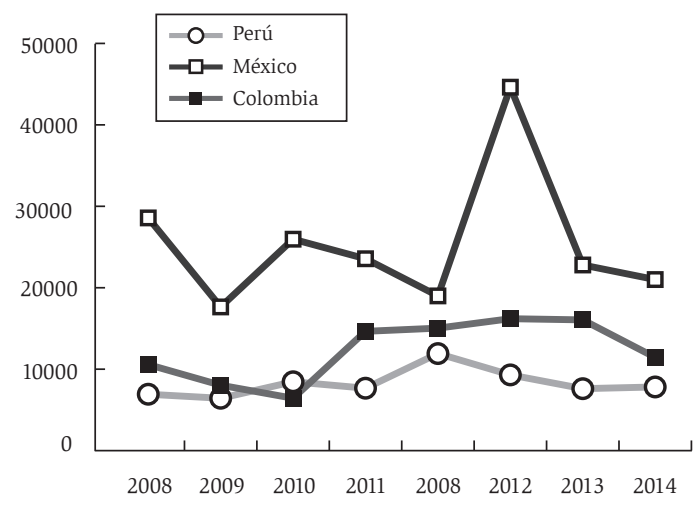

Fuente: Elaboración propia

Esta tendencia, en general al alza, tuvo solo tres puntos de inflexión, los cuales coinciden con los años en que las tres olas de la crisis económica mundial se manifestaron. Entre finales del 2007 y el año 2008 llega la primera ola de la crisis mundial desde Estados Unidos por cuenta de la burbuja inmobiliaria; posteriormente, en el 2012 aparece la segunda ola de la crisis, esta vez su nido tuvo lugar en Europa por la crisis de pagos que asoló al continente, aunque para este año México fue el único de estos tres países en los que disminuyó la IED; y sin haberse recuperado la economía mundial de esto, desde finales de 2014, pero con mayor intensidad en 2015, llegó la tercera ola de la crisis, esta vez producida por la caída de los precios de los commodities, centrada especialmente en los países "en vía de desarrollo”, y que, sin asomo de recuperación, continúa hasta estos días.

Ahora bien, en lo que va corrido de este siglo se configuró lo que se conoce como el superciclo minero, frente a esto:

Hay que precisar que no es ni por asomo un período parejo: el año 2003 se inició una lenta recuperación de los precios internacionales de los minerales, que dicho sea de paso venían de tocar fondo el año 2001 y 2002, y que llegó a un primer pico entre el 2007 y 2008. Luego se produce una 
drástica caída entre el 2008 y 2009, que rápidamente rebota, para alcanzar un nuevo pico entre el año 2011 y 2012 (De Chave, 2016).

Frente a lo anterior, es importante resaltar el hecho de que coinciden la primera ola de la crisis con la caída de precios y, paradójicamente, la segunda ola con el pico de estos. Lo anterior puede explicarse porque esta segunda ola se centró en las principales economías del mundo; sumado a esto, China se convirtió en el motor de crecimiento económico mundial, y fue el principal socio comercial de América Latina, sociedad centrada en la compra-venta de materias primas, además:

se comprueba una tendencia al alza en la inversión en la explotación de bienes naturales, principalmente en la región sudamericana, donde este rubro supuso el $43 \%$ del total de la entrada de IED en 2010 y el $57 \%$ en 2011, excluido Brasil. Se trata de inversiones en la explotación de materias primas para la exportación, fundamentalmente minería metálica, hidrocarburos y alimentos, impulsada por los altos precios de estas commodities en el mercado internacional (Omal).

Esta dinámica de alzas y caídas en la IED no es ajena a la ocurrida para la extracción de bienes naturales, esto igualmente dependiendo del año y de las circunstancias globales expuestas anteriormente, lo cual puede verse a continuación.

\section{Tabla2. IED para la explotación de bienes naturales (cifras en millones de dólares)}

\begin{tabular}{|l|c|c|c|c|c|c|c|c}
\multicolumn{1}{c|}{ País } & 2008 & 2009 & 2010 & 2011 & 2012 & 2013 & 2014 & 2015 \\
\hline Colombia* & 5139 & 5651 & 4918 & 7180 & 7945 & 8089 & 6313 & 8178 \\
\hline México** & 44915 & 1330.7 & 1470.4 & 8181 & 28911 & 5393 & 2225.9 & 6844 \\
\hline Perú*** & 3598.4 & 4542.3 & 5665.8 & 6048.8 & 6291.4 & 6271.7 & 6317.4 & 6327.8
\end{tabular}

Fuente: Elaboración propia 


\section{Gráfica 2. IED para la explotación de bienes naturales.}

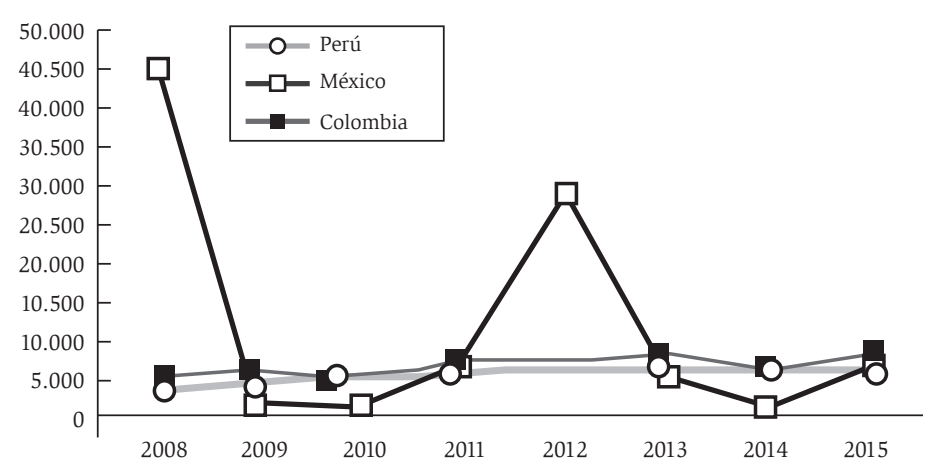

Fuente: Elaboración propia

Lo anterior genera que el sistema productivo de estos países se extranjerice, concentre y reprimarice, con todas las consecuencias económicas, fiscales, comerciales y socio-ambientales que esto conlleva; los principales Estados interesados en este sector continúan siendo Estados Unidos, Canadá, China y los países europeos, cuya inversión llega en manos de un puñado de empresas - Royal Dutch Shell, Chevron, ConocoPhilips, Exxon Mobil, BHP Billiton, Rio Tinto, Anglo American, Barrick Gold-y convierte a los países receptores en rentistas-extractivistas con economías primarioexportadoras totalmente dependientes del mercado mundial.

Ahora bien, es imposible negar la rentabilidad de esta actividad económica y las superganancias que genera; la cuestión es: ¿estos altos rendimientos económicos se ven reflejados en el grueso de la población de estos países?, o iesta errada lógica de acumulación infinita es otra forma más en la que se presenta el desarrollo clásico de concentración de capital a costa de la destrucción de la naturaleza y de retrocesos sociales, culturales y económicos para la mayoría? ¿Qué supuesto desarrollo les deja a los países la IED, especialmente la centrada en la extracción de bienes naturales? 
A pesar de estos altos niveles de inversión, las condiciones sociales no son las prometidas en el discurso de desarrollo que de manera coordinada manejan los Estados-gobiernos y las empresas extractivas; mientras que en las grandes capitales los índices sociales muestran algunos avances, en las regiones se presenta una disparidad respecto a lo presentado en las ciudades, a sabiendas de que es en estas alejadas zonas de los centros económicos y de poder donde se asientan los enclaves extractivos y, paradójicamente, donde menos o nulos beneficios se reciben.

En México, a 2008, 50,6 millones de personas no tenían lo suficiente para suplir su salud, educación, transporte, vivienda o vestido, ni siquiera dedicando todos sus ingresos a esto. Poco más de diecinueve millones sufrían de carencias alimentarias; de estos 7,2 millones vivían en ciudades, y 12,2 millones lo hacían en las zonas rurales (Unicef México, 2012). Además, este país tiene la tasa de ingreso familiar más baja y está en el segundo lugar en la tasa de desigualdad más alta de ingresos dentro de la OCDE. Continuando con esta lógica, al interior de la OCDE el país latinoamericano es el de menor gasto en protección social, el cual equivale al $7.4 \%$ del producto interno bruto.

El nivel de pobreza relativa es el segundo más alto de la OCDE —una de cada cinco personas es pobre-; en este mismo sentido, ningún otro país de los que integra dicha organización tiene la mayor proporción de población con la percepción de que no puede comprar alimentos suficientes (ver cuadro 3), y para cerrar este cuadro, México es uno de los pocos países que no tiene ningún tipo de seguro por desempleo (OCDE, 2014).

En el Perú la historia no es muy diferente. Aunque en general los índices en el país han mejorado ligeramente, estos no corresponden al alto nivel de inversión que se ha hecho en el país; además es muy importante resaltar que en los tres departamentos donde más se realizan extracciones de bienes naturales - Cajamarca, Huancavelica, y Apurímac-, a 2014, según el Instituto Nacional de Estadística e Informática -INEI-, el porcentaje de población con al menos una necesidad básica 


\section{Gráfica 3. Porcentaje de población con la sensación} de no poder comprar alimento suficiente

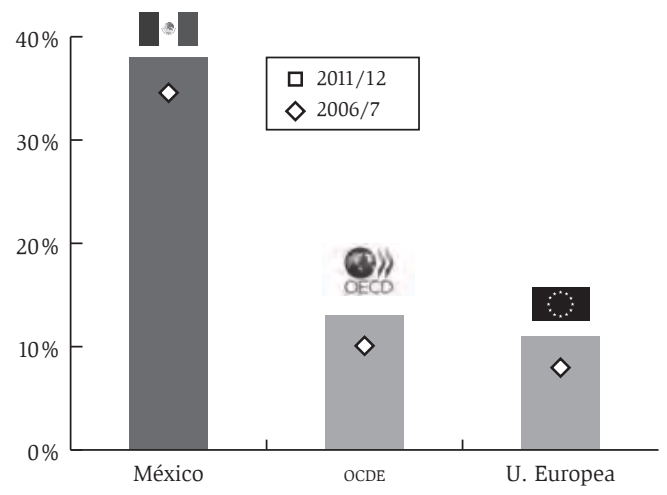

Fuente: OCDE.

insatisfecha - NBI- era de 27,8\%, 36,3\% y 22,2\% respectivamente, mientras que a nivel nacional era de $20,5 \%$.

Lo anterior se refuerza con lo que ocurre en Cajamarca, donde se encuentra la segunda mina más grande de oro del mundo, la mina Yanacocha, con inversión estadounidense, peruana y de la Corporación Financiera Internacional. Es en este departamento peruano donde, según el INEI, se encuentra la tasa más alta de población con pobreza y pobreza extrema: en 2010 el 50 \% de la población era pobre, cifra que ha sido una constante hasta estos días; para el año 2015, esta cifra a nivel nacional era de 3,8\% (Redacción Gestión, 2016).

En cuanto a la pobreza extrema, en 2013 Cajamarca presentaba un intervalo de $18,14 \%$ a $26,97 \%$, en el año siguiente este intervalo era de $15,16 \%$ a $23,22 \%$, y en 2015 fue de $16,63 \%$ a 23,89\%; además de esto, es el departamento con menor asignación para gasto público per cápita, mientras que la cifra nacional para ese año fue de 4,6\%. Entre 2014 y 2015, la línea de pobreza extrema creció en el sector urbano un 4,5\% y en la zona rural un 4,2\%; la línea de pobreza rural representa el 80,8\% de la del área urbana (INEI, 2016). 


\section{El caso colombiano}

Para empezar, es importante tener claro que Colombia no es un país minero, es un país con minerales, lo cual es bastante distinto. Colombia se ha caracterizado por ser un país agrario-ambiental, al cual se le ha cambiado su matriz productiva en gran medida por el discurso ambiguo del desarrollo y el subdesarrollo y por buscar participación de las rentas extractivas.

Ahora bien, para entender la dinámica del sector extractivo en el país y de la IED que se dirige hacia este, es fundamental entender y ver como determinante el conflicto armado que ha sufrido el país por más de cincuenta años, pero especialmente el surgimiento del paramilitarismo; por esto, es casi un deber civil hacer énfasis en que el paramilitarismo no fue, ni es un movimiento contrainsurgente, sino que desde que nació y hasta estos días es un proyecto político y económico.

En el país habría sido imposible que el sector extractivo hubiese alcanzado la dimensión que tiene en la actualidad si no se hubiera apoyado en el proyecto paramilitar para despojar a comunidades de grandes extensiones de tierra por medio de asesinatos selectivos, masacres y desterritorializaciones forzadas. A febrero de 2015 había registrados 6,9 millones de desterritorializados (Acnur, 2016), lo cual pone al país en el deshonroso segundo puesto con mayor cantidad de desterritorializados internos después de Siria.

De acuerdo a las cifras del Grupo de Memoria Histórica (2013), entre 1985 y 2012 ocurrieron 1982 casos de desterritorialización en el país, de los cuales 1166 fueron efectuadas por grupos paramilitares; de igual forma, según cifras de este grupo, entre 1981 y 2012 ocurrieron 16340 asesinatos selectivos, de los cuales los grupos paramilitares ejecutaron 8903.

Lo anteriormente expuesto frente a los intereses económicos que han estado tras el paramilitarismo se refuerza con investigaciones hechas por organizaciones como PAX (2014) y Cedins (2015), las cuales mues- 
tran las relaciones que estos ejércitos privados tuvieron con empresas mineras, puntualmente con Drummond y Prodeco, para la primera, y para la segunda, Anglogold Ashanti; además, cabe señalar que esta última empresa fue denunciada por Human Rights Watch debido a la alianza hecha con el Frente Nacionalista e Integracionista - FNI- en el Congo y así poder extraer oro en el norte de este país (HRw, 2005).

A esto se suman también las relaciones que entablaron empresas petroleras y de agronegocios, casos como el de la petrolera Perenco y las Auto Defensas Unidas del Casanare (Quevedo, 2012). José Darío Orjuela, comandante de este grupo paramilitar, confesó que Ocensa y Ecopetrol influían en los secuestros que realizaban; mientras que British Petroleum anualmente aportaba doscientos millones de pesos, además de en este departamento, en Meta y Arauca. En los noventa, los grupos paramilitares atacaron sindicatos y comunidades que se oponían a la extracción de petróleo: a Arauca llegó el Bloque Vencedores de Arauca, por petición de las empresas que operaban allí (Semillas, 2015).

Bajo la misma lógica, las empresas palmicultoras, aprovechando las desterritorializaciones masivas y las masacres cometidas por grupos paramilitares, especialmente en el Magdalena Medio, el Chocó y el nororiente colombiano, se han asentado allí para sembrar miles de hectáreas de palma africana; entre los casos más relevantes se pueden destacar los de Jiguamiandó y Curvaradó en el Chocó, el de la hacienda Las Pavas en el sur de Bolívar y la hacienda Bellacruz en el Cesar y el Catatumbo. Incluso, Carlos Castaño admitió que los paramilitares eran propietarios de cultivos de palma en el Urabá (Carrizosa, 2006). Como se ve, estos enclaves extractivos se ubicaron en zonas históricamente conflictivas y lograron estar allí violando los derechos humanos de los habitantes de esos lugares para favorecer intereses concretos.

Ahora bien, esta es tan solo una de las dimensiones características del extractivismo en el país; el discurso institucional proextractivo y de las empresas de este sector para ganar legitimidad ante el país y lograr 
entrar en sus regiones de interés está concentrado en la generación de empleo, el mejoramiento de los índices sociales, amplias ganancias fiscales y económicas, cuidado ambiental y el siempre citado desarrollo, no solo para el país, sino para las regiones donde se ubiquen los enclaves extractivos; pero estos temas no son más que un mito.

\section{Generación de empleo}

El sector extractivo es una actividad de capital intensivo, lo cual quiere decir que en su proceso utiliza más capital que cualquier otro factor de producción: por ejemplo, en el caso de la minería, "por cada millón de dólares invertido, se crean apenas entre 0,5 y 2 empleos directos" (Machado et al., 2012). Ahora bien, es necesario hacer un par de comentarios: los enclaves extractivos en sus fases iniciales requieren de grandes cantidades de empleados, fundamentalmente para abrir caminos, construir casas o para prestar seguridad, esto crea la falsa idea de que la necesidad de empleados por parte de la empresa será permanente. Sumado a lo anterior, esta clase de proyectos necesitan de conocimientos específicos, por lo cual se requiere de profesionales, que podrían ni siquiera provenir del país donde se ubica el proyecto, sino que son llevados de otros.

Por otro lado, en declaraciones recogidas por el diario El Tiempo (2015), la subdirectora de ManpowerGroup para la región andina señaló que, para el tercer trimestre de ese año, "la expectativa es de despidos más que de contrataciones” en el sector minero, ya que la perspectiva neta de empleo pasó de $-1 \%$ a $-4 \%$ de un trimestre a otro.

De igual manera, las plantaciones de monocultivos:

generan muy pocos empleos, en general de muy baja calidad, casi todos de carácter temporal, con bajos salarios y en condiciones de trabajo donde prima la mala alimentación, el alojamiento inadecuado y el incumplimiento de la legislación laboral vigente. Son frecuentes los accidentes y las enfermedades laborales (Grain, 2009). 


\section{Gráfica 4. ¿Cuánto empleo genera la minería?}

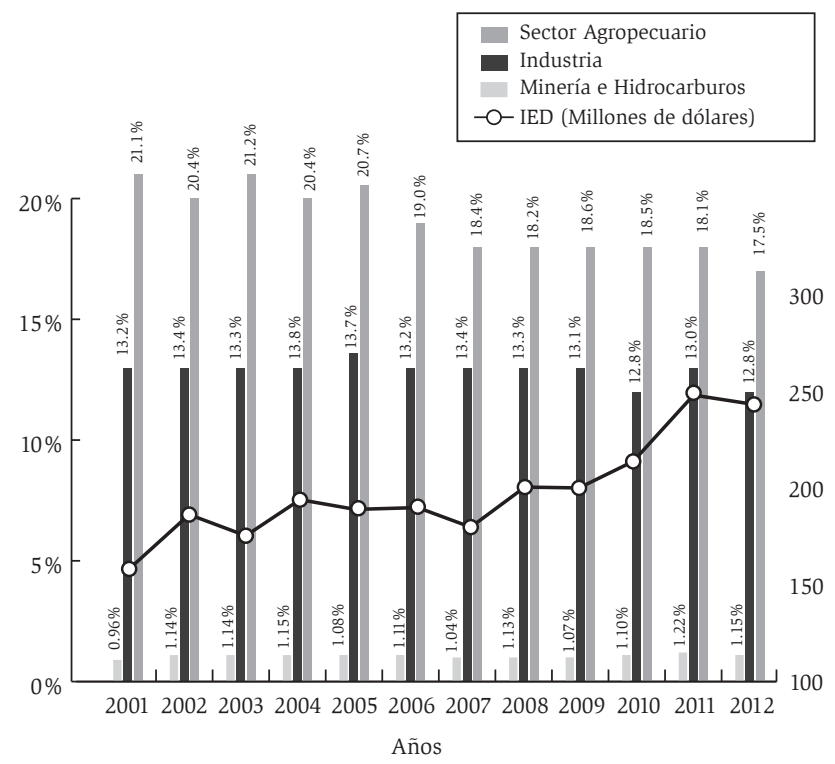

Fuente: El Tiempo

En un caso similar al de los enclaves mineros, para la construcción de hidroeléctricas, al principio del proyecto se necesitan grandes cantidades de empleados para la edificación de infraestructura, pero después de que estas entran en funcionamiento, los empleados requeridos necesariamente requerirán de conocimientos especializados.

\section{Dimensión socio-ambiental}

Como se vio anteriormente, los flujos de inversión hacia el país, a pesar de la crisis mundial, se han mantenido en niveles importantes. Esto ha generado que el PIB nacional se mantenga alto, al igual que el PIB minero, que aumentó de $\$ 2,72$ billones en 2002 a $\$ 4,5$ billones de pesos en 2009, es decir, en ocho años aumentó 65,4\% (PND, 2010); a 2014, la participación del sector extractivo fue de $13,26 \%$ en el PIB nacional, $7,26 \%$ del sector minero (Minminas, 2015) y $6 \%$ del sector petrolero 
(Fedesarrollo, 2015). Aunque es un porcentaje relativamente bajo en comparación, por ejemplo, al aporte al PIB generado por los establecimientos financieros, que en 2014 fue el sector que más aportó con $19,71 \%$ (Minminas 2015), se debe tener en cuenta que en los años de bonanza extractiva el aporte desde el sector era muy superior; la cuestión es que estos altos niveles de inversión no corresponden con los índices sociales de las poblaciones donde se centran los proyectos extractivos.

Entre los años 2008 y 2014 la posición del país en el ranquin mundial del Índice de Desarrollo Humano osciló entre el puesto 89 y el 97 dentro de 188 países, de acuerdo a los cálculos hechos por la ONU (PNUD, 2015); por otro lado, la desigualdad en el país no disminuye, Colombia es el segundo país más desigual de América Latina con un índice de Gini igual a 53,5 de acuerdo al Banco Mundial. Ejemplos claros de esto son que el $10 \%$ de la población más rica del país gana cuatro veces más que el $40 \%$ más pobre, o que el índice de Gini para medir la concentración de la tierra es de 0,86 (Justo, 2016).

Aunque estas cifras son muy preocupantes, lo son mucho más las de las zonas donde se ubican los proyectos extractivos, pues en estas es mucho más evidente que el discurso del desarrollo solo llegó como eso, como discurso cargado de promesas y engaños, se convirtió en un canto de sirena para sus habitantes, a quienes únicamente les han dejado los costos ocultos de estos proyectos.

Esto se puede evidenciar claramente con casos concretos como los ocurridos en municipios donde se desarrolla minería a gran escala, donde se explotan hidrocarburos y donde hay siembra de monocultivos. En estas áreas alrededor de los enclaves tiene lugar lo que podría llamarse como cultura extractiva ${ }^{3}$, donde se desarrollan círculos de miseria y

3 Esta cultura no debe entenderse como propia de las comunidades, por el contrario, se contrapone a la cultura que han construido históricamente las comunidades en 
convergen la prostitución, la proliferación de establecimientos dedicados a la venta de licor y juegos de azar, y se disparan los índices de consumo de drogas y de violencia, características propias de las economías extractivas.

Al ser tan pocas estas líneas, es imposible tocar las implicaciones de cada uno de los enclaves extractivos del país, pero al ser sus lógicas, dinámicas e impactos negativos tan similares, los párrafos siguientes se centrarán solo en uno de ellos.

Quizá el caso más aberrante, pero que a la vez muestra con más claridad lo que en realidad el extractivismo deja en las regiones, lo presenta la extracción de carbón. El país tuvo su pico de explotación en el 2012 cuando se extrajeron 89024 320,82 toneladas de este mineral (Upme, 2016); aumentar la extracción de este material ha sido una de las prioridades de los gobiernos de turno, lo que ha significado para los departamentos donde se explota un alza en las mal llamadas "regalías" (ver gráfica 5), especialmente en las regiones de La Guajira y el Cesar, donde se concentran dos de los mayores emprendimientos mineros en el país y que han tenido un índice de producción estable, a diferencia de las tendencias mundiales (ver gráfica 6). A pesar de la alta inversión que allí se desarrolla y de los grandes recursos que deberían llegar por "regalías", la mejora en la calidad de vida no se nota de ninguna manera, por el contrario, parece empeorar, simplemente basta con comparar algunos índices entre estos municipios que se volvieron mineros a la fuerza frente a municipios en los que no hay actividades extractivas (ver gráfica 7).

sus territorios, insertando nuevas lógicas y dinámicas que rompen el tejido social y generando círculos de miseria alrededor de los enclaves extractivos. El ejemplo más claro es que pone en riesgo la cultura campesina y su lógica de trabajar la tierra y vivir de ella; la alta circulación de dinero es uno de los pilares de la cultura extractiva, pues cambia las dinámicas laborales y sociales, sustenta el alto consumo de alcohol, el consumo de drogas y alimenta el sueño extractivo del crecimiento económico, y, por lo tanto, incide profundamente en el cambio de la matriz productiva local. 


\section{Gráfica 5. Distribución de regalías del carbón y otros minerales}

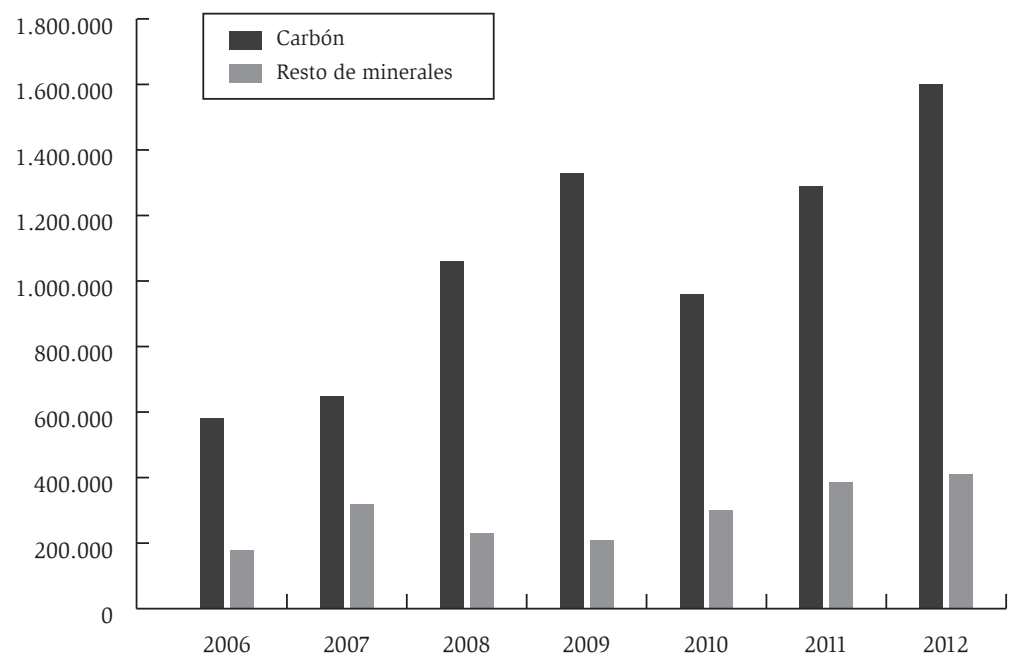

Fuente: Upme

\section{Gráfica 6. Producción de anual carbón}

Producción de carbón

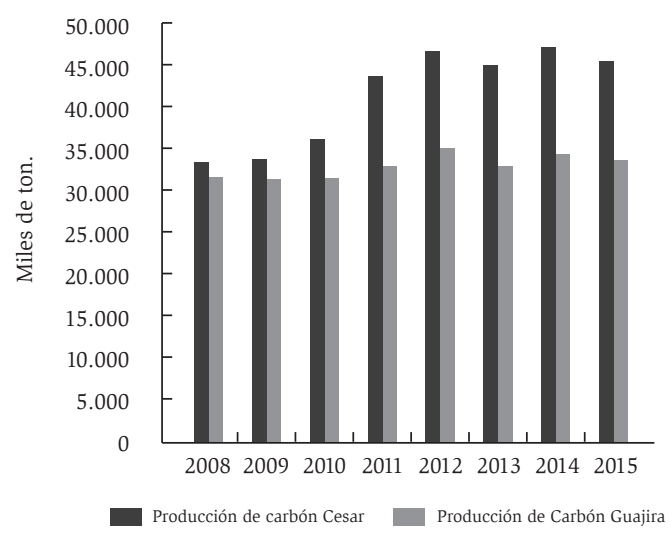

Producción nacional de carbón Ton (Miles)

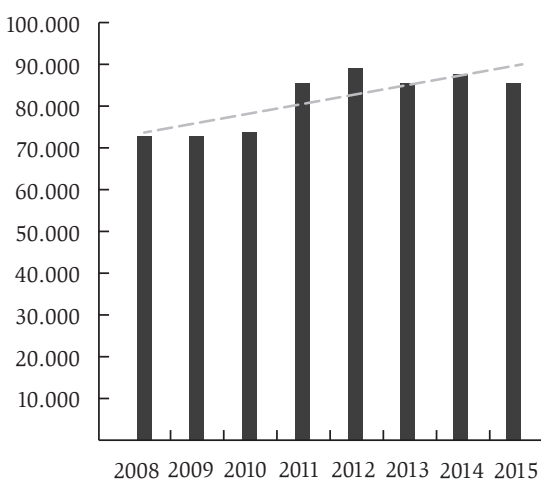

Fuente: Justicia Tributaria 


\section{Gráfica 7. Indicadores sociales de municipios productores de carbón. Diferencia de medidas de los municipios y del resto de municipios (no mineros) del departamento}

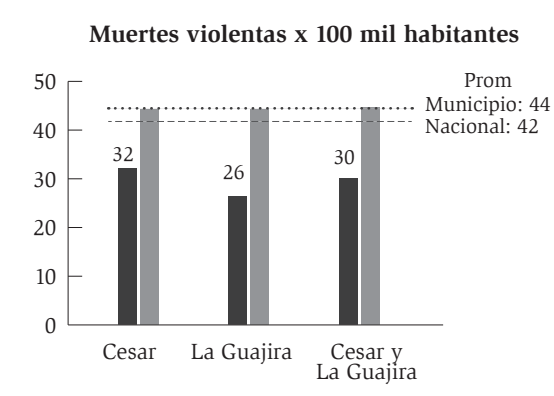

Necesidades básicas insatisfechas [\%]

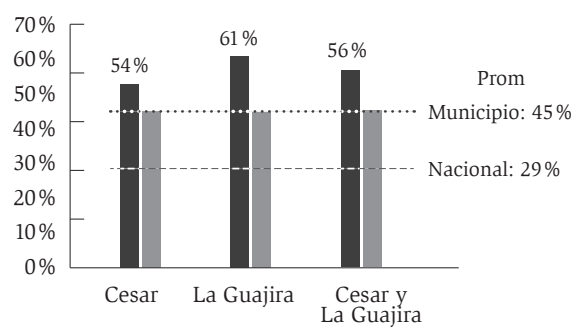

Mortalidad infantil $\mathrm{x}$ mil nacidos vivos

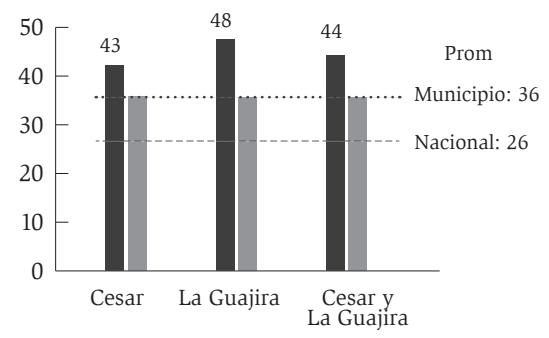

Población en condiciones de miseria [\%]

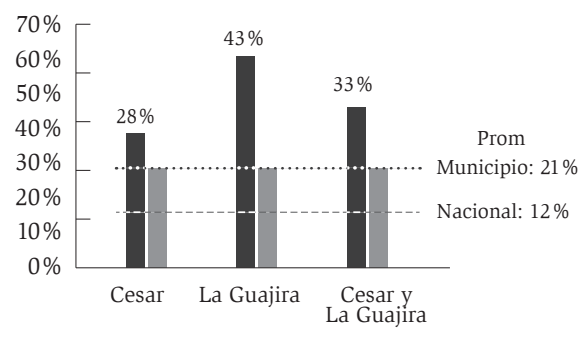

- Diferencia no significativa $\quad$ Significativamente mayor

- Resto del país

n Significativamente menor

Fuente: Rudas, 2012

A esto último se deben añadir los siguientes puntos:

- $\quad$ El $33 \%$ de los habitantes de los municipios que se ubican en el área de influencia de El Cerrejón y Drummond vive en condiciones de miseria, a nivel nacional este índice es igual a $12 \%$ (Ibidem)

- En los municipios donde se desarrolla gran minería de carbón, el índice de necesidades básicas insatisfechas (NBI) es de $56 \%$, el promedio nacional es de $29 \%$ (Ibidem)

- En los municipios vecinos a El Cerrejón, los casos de infecciones respiratorias agudas son la segunda causa de enfermedades; en esta 
región también se incrementó la mortalidad materna de 79 fallecimientos por cada 100 mil nacidos vivos en 2004 a 181,1 en el 2011. De ellas, el $93 \%$ pertenece a la etnia Wayyú (Cinep, 2013)

- En los municipios vecinos a El Cerrejón, la situación nutricional de niñas y niños menores de cinco años es crítica: $11,15 \%$ de desnutrición global o bajo peso, en comparación con el 3,43\% correspondiente al promedio nacional (Ibidem).

- A julio de 2014, en La Loma, Cesar, existen veintidós tipos de enfermedades, en su mayoría respiratorias como asfixia, asma y bronquitis, todas asociadas a la explotación de carbón (El Pilón, 2014).

- La pobreza extrema en La Guajira es de 25,7\%, tres veces mayor que el índice nacional (Justicia Tributaria, 2016).

- A 2013, 230 mil personas estaban en condición de pobreza extrema, cifra que representa cerca del $25 \%$ de la población de La Guajira (Ibidem).

- La Guajira rural registra una alta proporción de población en pobreza y en miseria, llegando a niveles del $91 \%$ y $80 \%$, respectivamente (Justicia Tributaria, 2016).

Estas cifras permiten ver cómo los altos índices de inversión para la extracción de bienes naturales a gran escala no representan mejoras en la calidad de vida de la población, por el contrario, las condiciones de vida de quienes habitan estos territorios empeoran.

A esto hay que añadirle algo que se deja de lado, pero que es de vital importancia entenderlo y enfrentarlo, y es el reemplazo del Estado-nación por una suerte de Estado extractivo-corporativo. ¿Esto qué quiere decir? Pues que, ante el histórico abandono del Estado Social de Derecho en las regiones, las empresas extractivas, basadas en la responsabilidad social empresarial, se toman atribuciones que corresponden al 
Estado, como la construcción de infraestructura, garantizar la salud o la educación, todo con el fin de legitimar las actividades de la empresa; es decir que el Estado, además de desentenderse de los problemas locales, genera los mecanismos para que las empresas lo reemplacen. Ante esto, cabe resaltar que la única forma en que el Estado hace presencia en estos territorios es mediante la fuerza pública.

Para complementar lo anterior, el abandono estatal llega hasta el punto que cuando los conflictos socio-territoriales se desarrollan entre las empresas y las comunidades, en algún punto del conflicto el Estado aparece, generalmente como una fuerza policiva contra las comunidades y favoreciendo los intereses de las empresas.

\section{Implicaciones político-fiscales}

Otro de los mitos que se ha construido alrededor de los proyectos extractivos es que pagan grandes cantidades de impuestos por sus actividades, pero investigaciones como las realizadas por la Contraloría General de la Nación, la organización Colombia Punto Medio y Justicia Tributaria, entre otras, han demostrado lo contrario.

En las últimas dos décadas, por cada dólar aportado al PIB por la minería y los hidrocarburos, el Estado percibe ingresos fiscales de menos de dieciséis centavos, incluyendo los años de bonanza de altos precios en el mercado mundial, lo cual se explica por una serie de descuentos y exenciones que ofrece el Estado sobre el impuesto a la renta; de igual forma, para el caso minero, desde el Código de Minas vigente se estableció que la actividad minera está exenta de pagar algunos impuestos a las entidades territoriales.

Ahora bien, en cuanto a la tributación nacional, es importante entender que en el país hay tasas de tributación nominales, es decir, lo que debería pagarse, y las tasas de tributación reales, esto es, lo que en realidad pagan las empresas al Estado. Entre 2007 y 2010 la tasa nominal para minería era del $33 \%$, pero después de deducciones y exenciones la tasa 
real fue de cerca del $10 \%$, y después del 2011, esta tasa era del $15 \%$ (ver gráfica 8).

Para cerrar, entre 2005 y 2010 las empresas mineras pagaron en promedio 878 mil millones de pesos anuales por impuesto a la renta, pero durante el mismo período por concepto de deducciones, descuentos y exencione se dejaron de percibir 1,78 billones de pesos. Es decir, por cada cien pesos pagados por este concepto, las empresas mineras tuvieron descuentos por más de doscientos pesos. (Contraloría General de la Nación, 2013).

\section{Gráfica 8. Regalías vs. deducciones tributarias}
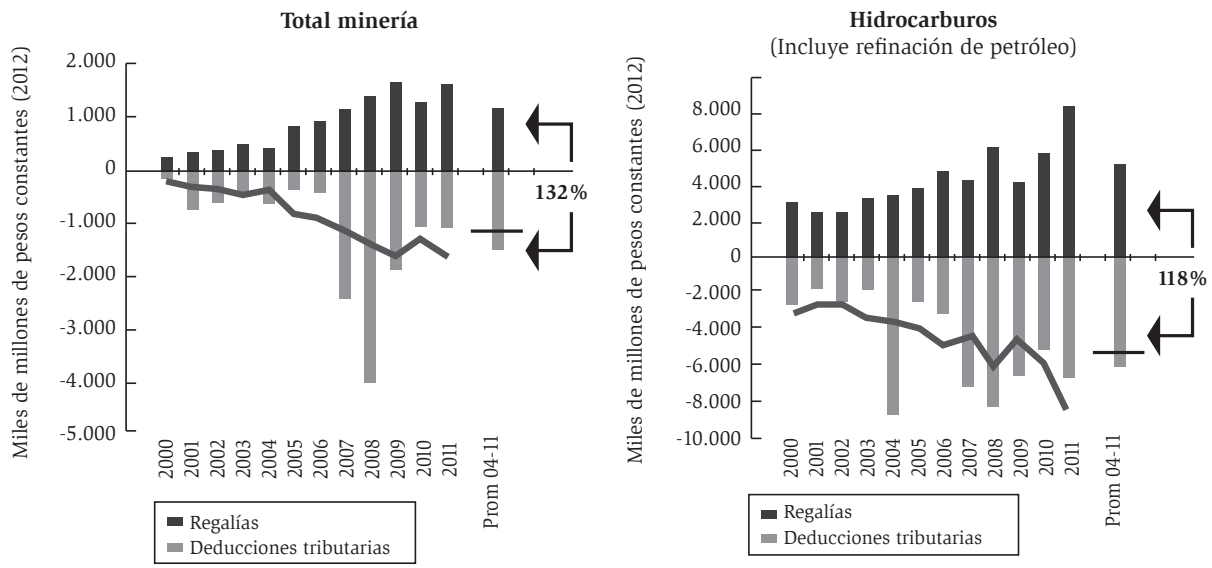

Fuente: Contraloría General de la Nación, 2013.

Por lo anterior, las empresas del sector han alcanzado un poderío económico y, muy tristemente, político tal que han debilitado al Estado, al punto que han logrado incidir en la construcción de políticas y tener influencia en diferentes esferas del gobierno para favorecer sus intereses.

\section{Neo-extractivismo y neo-desarrollismo}

En palabras de Eduardo Gudynas, en la gestión de los gobiernos progresistas en América del Sur "persiste la importancia de los sectores 
extractivistas como un pilar relevante de los estilos de desarrollo", destaca Eduardo Gudynas (2009b y 2010c). Siguiendo con sus reflexiones, si bien el progresismo sudamericano "genera un extractivismo de nuevo tipo, tanto por algunos de sus componentes como por la combinación de viejos y nuevos atributos", no hay cambios sustantivos en la actual estructura de acumulación. Con esto, el neoextractivismo sostiene "una inserción internacional subordinada y funcional a la globalización” del capitalismo transnacional. No solo se mantiene, sino que avanza "la fragmentación territorial, con áreas relegadas y enclaves extractivos asociados a los mercados globales”. Se sostienen, y “en algunos casos se han agravado, los impactos sociales y ambientales de los sectores extractivos”. Siguiendo con Gudynas, “más allá de la propiedad de los recursos, se reproducen reglas y funcionamiento de los procesos productivos volcados a la competitividad, eficiencia, maximización de la renta y externalización de impactos”. Entre los puntos destacables está "una mayor presencia y un papel más activo del Estado, con acciones tanto directas como indirectas”. Desde esta postura nacionalista se procura principalmente un mayor acceso y control por parte del Estado sobre los recursos naturales y los beneficios que su extracción produce. A partir de esta postura se critica el control de los recursos naturales por parte de las transnacionales y no la extracción en sí, incluso se acepta algunas afectaciones ambientales e inclusive sociales graves a cambio de conseguir beneficios para toda la colectividad nacional (Acosta, 2012).

Es importante entender que el neoextractivismo hace parte de lo que se ha conocido como desarrollo alternativo, el cual tiene dinámicas y lógicas distintas frente al desarrollo convencional, pero no se aleja de sus preceptos de crecimiento económico infinito y, por ende, el neoextractivismo está muy lejos de ser una alternativa al desarrollo, con lo cual sí buscaría salir de las lógicas del desarrollo clásico.

Ahora bien, en América Latina tomó fuerza el término de neodesarrollismo, especialmente en los gobiernos progresistas, el cual buscaba hacer un quiebre y separarse del neoliberalismo imperante en la región, idea que surgió en el seno de la Cepal. De acuerdo con Katz, este 
enfoque tiene cinco objetivos: el primero, una mayor intervención del Estado con el fin de salir del subdesarrollo, fundamentando esto en que los mercados fuertes son imposibles de conseguir sin Estados fuertes, lo cual indica que de igual forma continúa apoyando el capital; el segundo objetivo corresponde a políticas económicas que buscan alentar la competitividad, reducir la dependencia financiera de los flujos de capital y limitar el déficit fiscal; el tercero es la industrialización, al considerar que la expansión de la industria debe ser una prioridad para las economías medias, se consiente el extractivismo para conseguir recursos que permitan dicha expansión, la cual sirve a las multinacionales y a la inversión extranjera; en esta misma vía va el cuarto objetivo, reducir la brecha tecnológica, fundamentalmente, basándose en la transferencia de tecnología que pueden hacer las multinacionales, de ahí la importancia que se le da a la inversión extranjera; por último, el quinto objetivo es imitar el modelo exportador del sudeste asiático, esto sin tener en cuenta el contexto geopolítico en el que se desarrolló este sistema, desconociendo que es una propuesta anticomunista y dejando de lado las necesidades de Latinoamérica.

Con base en lo anterior, algunos de los países latinoamericanos como Bolivia, Ecuador y Venezuela han tomado la decisión de centrarse en el extractivismo como fuente de generación de ingresos con el fin de utilizarlos para ayudar al proceso de construcción de vida digna o sumak kawsay, esto a costa de ir en contra de los intereses de grandes sectores de la población de estos países, donde los gobiernos fueron apoyados por movimientos sociales en búsqueda de una ruptura de las históricas condiciones sociales, económicas y políticas que se vivían allí.

Para el caso de Ecuador y Venezuela, ambos integrantes de la Opep, el primero el más pequeño de la organización y el último una de las mayores potencias a nivel mundial por sus reservas y nivel de producción, como se ha expresado anteriormente, han centrado sus rentas petroleras para mejorar las condiciones de vida de la población, con pros y contras por esta actividad. 


\section{Gráfica 9. Promedio anual de barriles de petróleo producidos diariamente en Venezuela.}

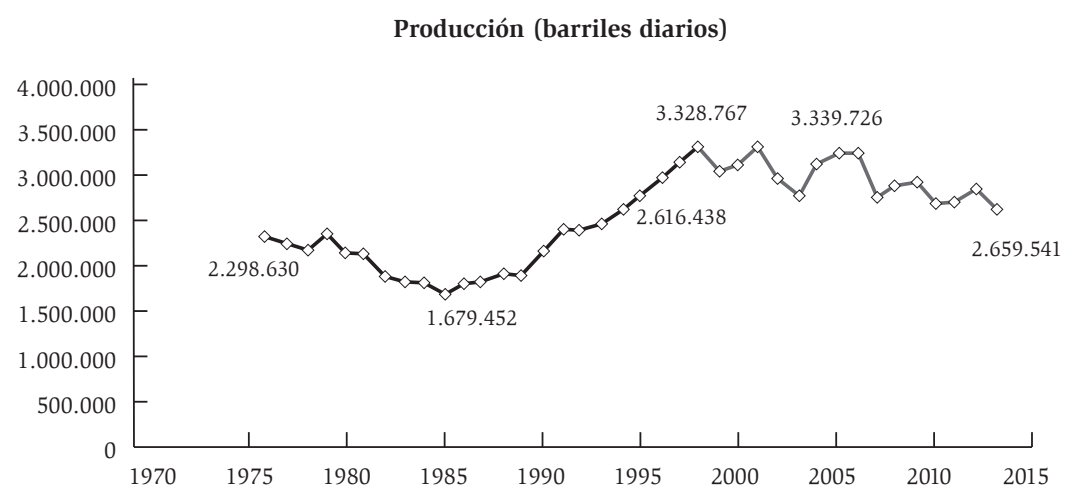

Fuente: Banco Central de Venezuela, 2013

Entre 2001 y 2014, la empresa pública de petróleo de Venezuela -PDVSA - destinó 26080 millones de dólares en inversión social, entre los diferentes montos hechos por la empresa se destacan los 7108 millones de dólares destinados a Misiones Sociales, donde se encuentran rubros dedicados a vivienda, alimentación, proyectos energéticos y otros generados desde las comunidades, y los programas Barrio Adentro y el Ribas; 22 millones para el Fondo Asfalto, cuyos recursos se destinan a la construcción de infraestructura; 6854 millones para el Fondo Chino para impulsar el desarrollo socio-productivo y la industrialización del país; 208 millones para el Fondo de Ahorro Nacional de la Clase Obrera y Fondo de Ahorro Popular, recursos destinados al pago de las prestaciones sociales y aportes al régimen pensional de los servidores públicos; 10400 millones que se destinaron para el Fondo de Desarrollo Nacional -Fonden-, con el fin de ejecutar grandes obras de infraestructura (PDVSA, 2014).

El porcentaje del PIB venezolano invertido en gasto público social pasó de 0,9\% en 1990 a 6,1 \% en 2012 según el Sisov; gracias a esta inversión 


\section{Gráfica 10. Ingreso anual por exportaciones petroleras}

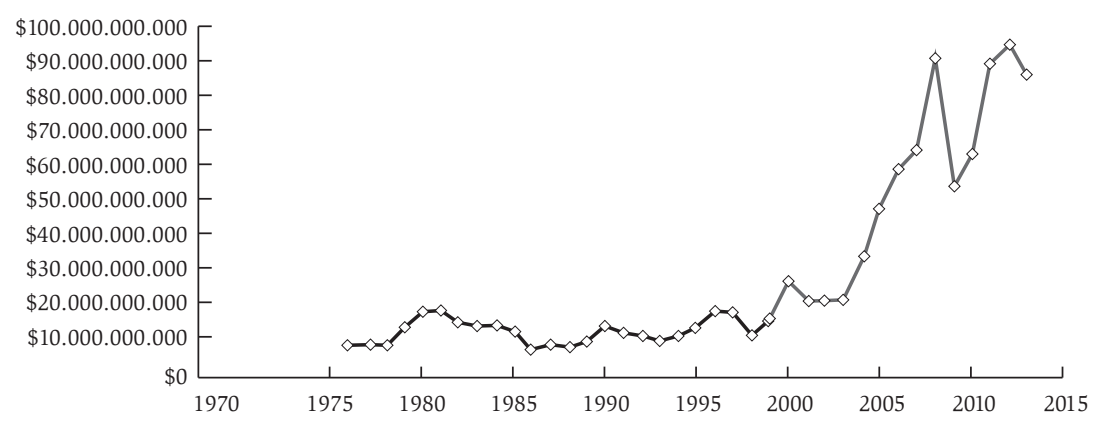

Fuente: Banco Central de Venezuela, 2013

social realizada por el gobierno venezolano han logrado cumplir con algunas de las Metas del Milenio ${ }^{4}$. Según el INEI, el índice de Gini para Venezuela es de 0,3928 , siendo el más bajo de América Latina. De esta forma:

entre 1982 y 1998 ingresaron al Estado un total de 230 mil 576 millones de dólares, de los cuales se destinaron 90 mil 141 millones (39\%) en el desarrollo social. Mientras que el período comprendido entre 1999 y 2015, la nación recibió la suma de un billón 280 mil 609 millones de dólares, de los que el Gobierno Bolivariano ha invertido 914 mil 148 millones $(71,4 \%$ ) para cubrir las necesidades de los venezolanos (Nodal, 2016).

4 Según el INEI son: reducción de la pobreza extrema y del hambre; eliminación de disparidades de género en la educación primaria y secundaria; erradicación del analfabetismo entre la población juvenil; acceso gratuito a las medicinas y al tratamiento de la infección por VIH; reversión de la tendencia de casos de tuberculosis; incorporación de principios de desarrollo sostenible en las políticas y los programas nacionales e invertir la pérdida de recursos del medio ambiente; diversidad biológica; acceso sostenible al agua potable y cobertura de recolección de aguas servidas; disponibilidad de los beneficios de las nuevas tecnologías, especialmente las de información y comunicación; y ampliación y fortalecimiento de mecanismos de cooperación para el desarrollo. 
En contraste con lo anterior, en los estados venezolanos donde se realiza explotación petrolera, los índices sociales muestran que allí no se han logrado los avances que sí se han alcanzado en el grueso del país: en el estado Zulia, el porcentaje de NBI es de $32 \%$, mientras el nacional es de $27 \%$ (INEI, 2014); de igual forma, de acuerdo con esta institución, a 2013 la pobreza en Venezuela fue del 32,1\% en los estados Monagas, Apure y Portuguesa, regiones donde se explota petróleo, allí su población no cuenta con los recursos suficientes para suplir la canasta básica; en Anzoátegui, el índice de pobreza extrema es del $11 \%$, mientras que en Falcón es del 11,6\%. A finales de 2013, la pobreza extrema en Apure, Monagas y Sucre superaba el $20 \%$.

Para el caso ecuatoriano, desde los años setenta el petróleo ha sido la principal exportación del país, por cada US\$100 que ingresan al país por exportaciones, US\$60 corresponden a la exportación petrolera. Entre 1970 y 2012, el promedio de IED fue de US\$340 millones, en este mismo periodo de tiempo las exportaciones petroleras alcanzaron un monto total de US\$123 mil millones; en 2012, de los US\$23 769 millones que se exportaron, US\$13 791 millones fueron de petróleo y derivados, mientras las importaciones llegaron a US\$24 017 millones. (Banco Central, 2013). Esto muestra la alta dependencia económica que tiene este país de la extracción petrolera.

Según el Banco Central Ecuatoriano, desde los años ochenta el petróleo ha tenido un peso entre el $30 \%$ y el $40 \%$ del presupuesto nacional de ese país, incluyendo las políticas sociales estatales. A pesar de esto, en la actualidad, el sector petrolero solo aporta entre el $10 \%$ y el $15 \%$ del PIB, fundamentalmente porque la producción y el precio en el mercado mundial han caído.

Sin embargo, las cifras generadas por la extracción petrolera no significan mejoría social para los ecuatorianos, y aunque es necesario reconocer que se han logrado avances sociales, la desigualdad y la pobreza continúan en cifras altas (ver gráfica 11). 


\section{Gráfica 11. Pobreza por necesidades básicas insatisfechas}

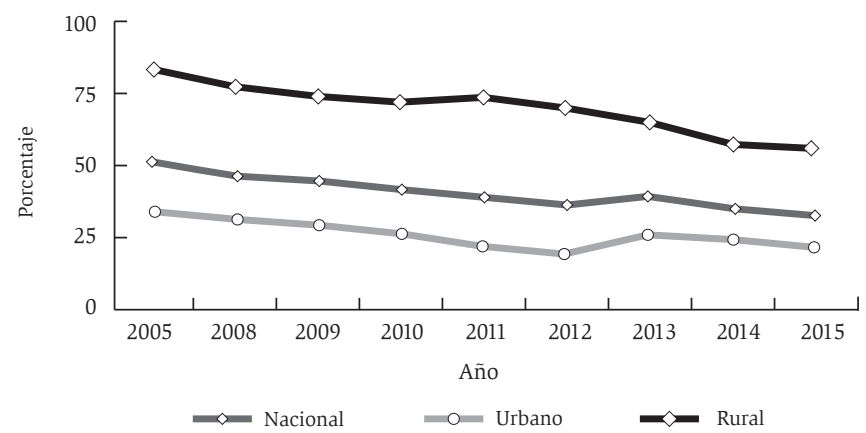

Fuente: Ministerio Coordinador de Desarrollo Social

Como puede verse, las cifras del sector rural son muy superiores a las nacionales. Es importante recordar que es allí donde se realiza la extracción de los bienes comunes; de igual forma, la pobreza de ingresos es mayor en este sector (ver gráfica 12).

\section{Gráfica 12. Incidencia de la pobreza de ingresos}

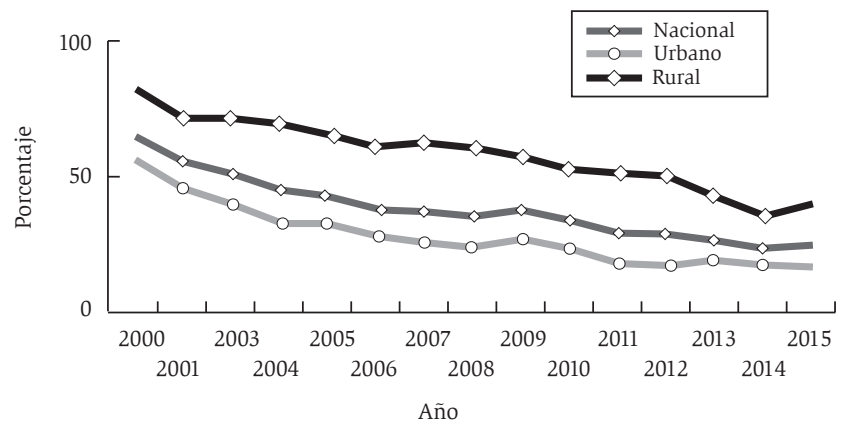

Fuente: Ministerio Coordinador de Desarrollo Social

Además, en el 2013, el Inec presentó datos preocupantes sobre el tema laboral. En un solo año, el desempleo bajó menos de medio punto, de $5,20 \%$ a 4,89\%, pero la ocupación plena también disminuyó, de 
$50,11 \%$ a 46,92\%; lo anterior demuestra la falsa idea de que el sector extractivo genera empleo, en especial teniendo en cuenta que para el año del informe aún estaba en su apogeo.

Ahora bien, para el caso boliviano, el presidente Evo Morales busca fortalecer su proyecto de gobierno con lo que denominó extractivismo social, centrado en la extracción de gas, petróleo y minerales; la IED en Bolivia en los últimos años ha sufrido altas y bajas (ver gráfica 13). De acuerdo con el Banco Central Boliviano, la IED a 2014 fue de 1482 millones de dólares, de los cuales 1140 millones correspondían al sector extractivo, siendo el sector hidrocarburos el de mayor inversión.

\section{Gráfica 13. Evolución de la IED}

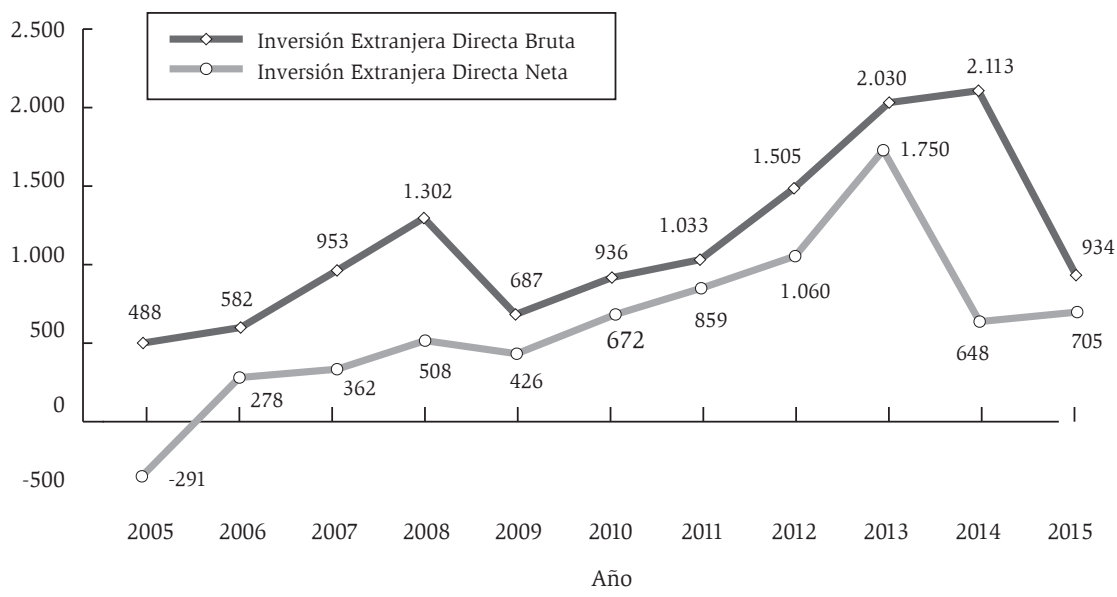

Fuente: Banco Central de Bolivia

Ahora bien, respondiendo a una dinámica mundial, la exportación de hidrocarburos cayó en el presente año, según el INEI, en un 49,5%: de enero a abril de 2016 las ventas de estos fueron de 769,9 millones de dólares, mientras que en este mismo periodo de tiempo, pero en 2015, esta cifra era de 1524,8 millones de dólares. Según este organismo, las 
exportaciones de Bolivia disminuyeron en un $29,8 \%$, siendo los sectores de hidrocarburos, manufacturas y minerales los más afectados, lo que demuestra la alta dependencia que tienen del mercado mundial.

Bolivia tampoco constituye una excepción a los problemas sociales que genera la extracción de bienes naturales. A pesar de los esfuerzos realizados por el gobierno del mas, según la Udape, entre 2007 y 2014 la pobreza extrema en Bolivia pasó del 37,3 \% al 17,3 \% , aunque el grueso de la población que sufre de esta condición económica continúa en el sector rural (ver gráfica 14).

\section{Gráfica 14. Porcentaje de población boliviana en pobreza extrema.}

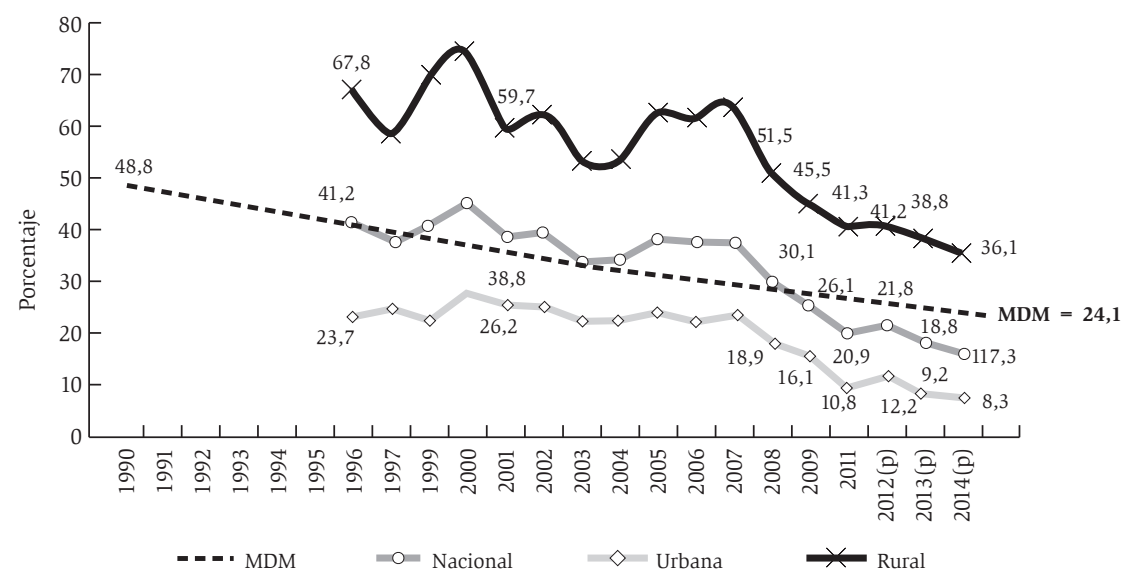

Fuente: Udape

A 2014, Bolivia tenía cerca de dos millones de personas en extrema pobreza, de las cuales 641 mil personas habitaban en el sector urbano y las restantes el sector rural. Además de esto, el índice de Gini para la distribución del ingreso en Bolivia ha sufrido avances y retrocesos, esto último en el sector rural (ver tabla 1). 


\section{Tabla 3. Distribución del ingreso per cápita mensual}

Bolivia: Indicadores de distribución del ingreso per cápita mensual

\begin{tabular}{|l|c|c|c|c|c|c|}
\hline \multicolumn{1}{|c|}{ Descripción } & 2008 & 2009 & 2011 & 2012 & 2013 & 2014 \\
\hline ÍNDICE DE GINI & 0.53 & 0.50 & 0.47 & 0.47 & 0.48 & 0.50 \\
\hline Bolivia & 0.48 & 0.45 & 0.41 & 0.42 & 0.42 & 0.44 \\
\hline Área Urbana & 0.56 & 0.53 & 0.54 & 0.55 & 0.53 & 0.57 \\
\hline Área Rural & 13.91 & 14.72 & 11.64 & 12.92 & 11.54 & 12.22 \\
\hline BUZÓN DE PERCENTILES (En porcentaje) & & & & \\
\hline Percentil 90 / Percentil 10 & 19.95 & 2.88 & 2.87 & 2.87 & 2.98 \\
\hline Percentil 90 / Percentil 50 & 3.19 & 2.97 & 0.25 & 0.24 \\
\hline Percentil 10 / Percentil 50 & 0.23 & 0.20 & 0.25 & 0.22 & 0.25 \\
\hline Percentil 75 / Percentil 25 & 3.43 & 3.31 & 3.17 & 3.35 & 3.32 & 3.19 \\
\hline Percentil 75 / Percentil 50 & 1.79 & 1.78 & 1.72 & 1.73 & 1.74 & 1.73 \\
\hline Percentil 25 / Percentil 50 & 0.52 & 0.54 & 0.54 & 0.52 & 0.53 & 0.54 \\
\hline
\end{tabular}

Fuente: Instituto Nacional de Estadística. Encuestas de mejoramiento de condiciones de vida (Mecovi 1999-2002). Encuesta de hogares (2005 - 2014)

Notas:

(1) No se calcularon estos indicadres para la Encuesta Continua a Hogares 2003-2004, por tanto no existe información para este período.

No se realizó la Encuesta a Hogares 2010.

A partir de 2008 no se realizan imputaciones en los ingresos.

Como se observa, en el área rural es donde existe mayor concentración del ingreso. Mientras se continúa ampliando la frontera extractiva, en lugar de disminuir, esta concentración aumenta sin dejar beneficios para las comunidades.

Pero estas no son las únicas críticas que recibe el neoextractivismo. Las objeciones a este "modelo de desarrollo" pasan por la relación con el ambiente y críticas económicas y políticas. A pesar del fortalecimiento 
de las empresas estatales para dejar una mayor participación de las rentas extractivas, o de la nacionalización de los bienes naturales, los gobiernos progresistas en América Latina no tienen una visión crítica frente al extractivismo como actividad, sino frente a quienes se quedaban con las rentas; es por esto que, ante el ascenso de gobiernos de izquierda, el modelo no se detuvo, sino que se fortaleció y tuvo algunos cambios.

Lo anterior abre la puerta para discutir el papel del Estado, pues mucho se ha dicho frente al "Estado mínimo" que es necesario para que las empresas extractivas logren desarrollar sus actividades con la mayor facilidad posible, pero, cabe preguntarse, iy si no es un Estado mínimo?, ¿y si es un Estado mínimo solo para proteger a su población, pero uno fuerte para dar garantías a las empresas que invierten o quieran invertir? Ese Estado fuerte puede entenderse desde la corporativización del Estado y el fortalecimiento de algunas instituciones y el debilitamiento de otras para facilitar el accionar del mercado, algo que podría resumirse en lo que se hizo durante los gobiernos Uribe para generar seguridad económica y así aumentar la IED en el país: el fortalecimiento de algunos ministerios y de la fuerza pública, así como la intromisión de la empresa privada en la redacción y aprobación de leyes, esto en contravía de la poca o nula presencia del Estado en las regiones del país y la violación y no garantía de los derechos de los ciudadanos.

Ahora bien, el neoextractivismo continúa reproduciendo lógicas y dinámicas del extractivismo clásico. Ambas expresiones y los gobiernos que las impulsan consideran algunos territorios como de segunda categoría o socialmente vaciables (Svampa, 2008) y, con el fin de permitir actividades extractivas, continúan con la idea de alcanzar algún tipo de "desarrollo" apropiándose de los bienes de la naturaleza, generando de igual forma impactos negativos socio-ambientales, pero buscando legitimar estas actividades con programas para la reducción de la pobreza y cerrar la brecha social con los recursos que generan estas actividades, aumentando la tributación, incluso renegociando contratos; tal vez el ejemplo de mayores cambios lo dio Bolivia desde que 
el mas llegó al poder, pues “la administración de Evo Morales en 2006 impuso la renegociación de contratos con las empresas petroleras, elevó las regalías y tributaciones al 50\%” (Gudynas, 2009). La diferencia más fuerte entre estos modelos, fundamentados en esas superganancias y su redistribución, es que estos gobiernos progresistas buscan ganar legitimidad entre la población - aunque esto último es igual en los gobiernos conservadores-.

Cabe señalar que otros países progresistas en Latinoamérica, como Uruguay y Brasil, han venido aplicando también actividades dentro del neoextractivismo, puntualmente en el sector agro-forestal, concentrando esta actividad en monocultivos, bajo la lógica del extractivismo que se centra en la exportación y que, como es característico de los enclaves extractivos, genera poco empleo, pero también profundos problemas socio-territoriales ${ }^{5}$.

Una de las mayores críticas que se les hace a los gobiernos progresistas y a su modelo extractivo es el fortalecimiento, dependencia y subordinación comercial a instituciones multilaterales como la omc y a acuerdos comerciales como los TLC, esto hace que estos gobiernos se deban mover bajo los lineamientos que imponen tanto las instituciones como los acuerdos; por lo tanto, Suramérica continúa teniendo un papel subordinado a los mercados centrales. Es así como se vuelven totalmente dependientes del mercado mundial, lo que implica desregular la legislación para poder hacer atractivos los países a la IED. Esto se convierte en un juego por saber cuál de estos países brinda los mayores beneficios y garantías para el capital, y es acá donde empieza el problema ambiental, pues se concibe al ambiente como un factor productivo, y por lo tanto, las facilidades ambientales se presentan como un plus a la hora de escoger el país donde se invierta; ahora bien, como se comentó anteriormente, los países progresistas se inclinaron por fortalecer las

5 Para saber más, ver: "Campesinos despojados de medios de vida", Desde Abajo, 2015. 
instituciones comerciales convencionales, esto a sabiendas de que en el pasado:

los gobiernos sudamericanos apoyaban también otras instituciones internacionales que buscaban cambios alternativos para el comercio global. Desde 1965 a los inicios de la década de 1990, se creó y apoyó la UNCTAD [...], para promover el comercio sur-sur, contribuir a mejorar los términos de intercambio frente a los países industrializados, y generar otras regulaciones comerciales. A su vez, desde la UNCTAD se fundó el Fondo Común para los Commodities [...], que entró en vigor en 1989, cubriendo varios productos agropecuarios y mineros, apuntando a desarrollar nuevos mercados y aliviar la pobreza. A su vez, la UNCTAD y el CFC crearon los llamados Organismos Internacionales en Bienes Primarios [...], con la finalidad de regular los mercados y el comercio global, entre otros varios aspectos (Gudynas, 2009).

Como se ve, con estos organismos existían otras formas de relacionamiento comercial, incluso mucho más favorables en términos de intercambio, pero fueron dejados de lado, fundamentalmente, por caer en prácticas empresariales como la competitividad y la búsqueda de altos réditos económicos.

Retomando el tema ambiental, este aspecto presenta grandes similitudes entre las dos clases de extractivismo acá estudiadas, pues claramente los impactos ambientales negativos de estas actividades se mantienen, a pesar del malintencionado discurso de que todo problema ambiental que surja puede solucionarse con tecnología, además de que replican la lógica de externalizar estos impactos, incluso invisibilizándolos y desconociéndolos.

Casos paradójicos son los que se viven en Ecuador y Bolivia, donde después del ascenso de gobiernos progresistas y de un ejercicio constituyente se reconocieron los derechos de la naturaleza a fin de tener una relación distinta con esta, pero sin que importara: en ambos países se ha abierto la posibilidad de desarrollar actividades extractivas en 
áreas protegidas o territorios ancestrales; esta es una de las razones más fuertes por las que sus gobiernos han perdido legitimidad y apoyo de quienes en un principio los respaldaron. Incluso se ha llegado a chantajear a la población de estos países diciendo que si no se desarrollan las actividades extractivas no se podrán seguir implementando programas sociales para la población y exponiendo, además, que las riquezas naturales no pueden dejarse sin explotar. Quizás el caso más recordado sea la apología hecha por el presidente Correa frente a estar sentados como mendigos sobre un saco de oro.

Como complemento de lo anterior, la violencia estatal y paraestatal es un factor compartido tanto por los gobiernos neoliberales como por los progresistas, tal como se sucedió y sucede en Colombia, pues es utilizada como un medio para lograr despoblar territorios y poder así explotar con mayor facilidad los bienes naturales. Resultan emblemáticos casos como el de Máxima Acuña en el Perú, donde ella y su familia son hostigados por personal de la minera Yanacocha ${ }^{6}$ para que abandonen su propiedad y así poder explotar el oro que hay allí.

Igualmente, en Ecuador el presidente Correa, contrario a su campaña y a quienes la apoyaron, ha buscado explotar yacimientos de petróleo en la Amazonía, ante lo cual las comunidades indígenas y organizaciones ambientalistas han levantado su voz de protesta, por lo que el gobierno ha reprimido de manera violenta a los manifestantes que se oponen a la explotación en esta zona; de igual manera, ha ordenado cerrar varias ONG que no comparten su idea de explotar bienes naturales, la más reciente ha sido la ONG Acción Ecológica que, entre otras acciones, ha apoyado a la comunidad shuar ante la represión estatal que busca favorecer a una minera china ${ }^{7}$.

6 "Perú: Nuevo ataque contra activista de la tierra Máxima Acuña, a dos días de visita internacional”. Amnistía Internacional.

7 “Ecuador: Gobierno cierra ONG Acción Ecológica”. Servindi. 
Por su parte, Evo Morales ha utilizado la fuerza para reprimir a quienes se han opuesto a sus proyectos: el caso más claro es el ocurrido en el parque nacional Tipnis, por el cual se ha proyectado la construcción de una carretera ${ }^{8}$ que dividiría este territorio, por lo que las comunidades levantaron su voz para oponerse al proyecto. Como resultado, hubo decenas de heridos y una grave crisis política ${ }^{9}$. Así pues, a través de la violencia se busca implementar enclaves extractivos a lo largo del territorio suramericano.

\section{Conclusiones y caminos}

Como se ve, esta forma de extractivismo acogida por los gobiernos de izquierda de Latinoamérica es aceptada como pilar del "desarrollo" fundamental para cerrar la brecha social en los países progresistas, pero este planteamiento ha hecho que se confunda el desarrollo con el crecimiento económico. Frente a esto es necesario aclarar que, en un planeta con bienes finitos, el crecimiento infinito no es posible; es así como el progresismo latinoamericano que está en el poder no ha criticado la concepción occidental de desarrollo ni ha generado alternativa alguna frente a este.

Así pues, los Estados progresistas de América Latina aceptaron los principios fundamentales del neodesarrollismo y los aplicaron a sus principales proyectos de gobierno, aumentaron la intervención del Estado en el sector, su competitividad en el mercado mundial para ganar socios comerciales, han intentado lograr cierto nivel de industrialización en sus países, en parte basados en las ganancias obtenidas por la bonanza del sector y por la transferencia tecnológica que han logrado obtener de las empresas extranjeras que llegan allí, y por último, han

8 La infraestructura es fundamental para desarrollar proyectos extractivos, tanto por el ingreso de maquinaria y personal, como para poder transportar lo que se explote; tener buena infraestructura de transporte reduce costos para las empresas.

9 "Pese al rechazo indígena, el gobierno de Bolivia quiere construir una carretera en una reserva ecológica”. Infobae. 
logrado aumentar sus niveles de exportación; pero esto no ha servido para romper las lógicas y dinámicas del desarrollo clásico, sino que incluso las ha profundizado.

Como modelo de desarrollo, no hay, sin embargo, diferencias sustantivas entre el extractivismo clásico y el neoextractivismo. Solo hay continuidad o profundización de la primacía del patrón productivo primario exportador (Lander, 2014). Ahora bien, todo esto hay que verlo y entenderlo en el contexto de los altos precios de las materias primas. Con la caída de estos, la situación cambia totalmente, el descenso de los precios coincide con la caída en la popularidad y legitimidad de los gobiernos progresistas que, al no contar con los recursos económicos de años anteriores, no logran justificar sus formas de gobernar.

Es acá donde se abre la discusión de qué tan útil es el hiperpresidencialismo sin el reconocimiento de las necesidades y los sentires de quienes aportan y aportaron en la construcción de una nueva forma de hacer política, y cabe preguntarse qué tan bien se está haciendo el trabajo de base en estos países, pues ante las mejores condiciones sociales alcanzadas, parte del sector social beneficiado por las políticas gubernamentales cambia sus visiones para apoyar a otros sectores políticos, al no sentirse ya representado ideológicamente con los gobiernos progresistas, pues siente que las ayudas gubernamentales disminuyen por las condiciones anteriormente expuestas; esta es una de las grandes fallas del paternalismo estatal eterno.

Pero es necesario resaltar que estos gobiernos han ayudado a contener al capital y al imperialismo, aunque la discusión de fondo sigue sin saldarse: ¿cuál es la alternativa al extractivismo? Además, existe otra mucha más grande y difícil: ¿cuál es la alternativa al "desarrollo”? Quizás, una forma de superar el modelo extractivo imperante puede ser rediversificar la matriz energética; cuando ocurra esto, también se rediversificará la matriz productiva, pues como se sabe, dentro de esta matriz, los países latinoamericanos le dan un peso muy importante a la 
explotación de energéticos ${ }^{10}$ y a la producción energética. Al tener esto en cuenta, si la producción energética se realiza con fuentes alternativas, estos países no se concentrarán en explotar carbón, petróleo u otra fuente energética primaria, y sí en otros sectores, como la producción de alimentos, o en la producción industrial; así, se saldría de la lógica impuesta a Latinoamérica de ser simplemente una canasta de materias primas para las economías centrales y con esto sería posible buscar los recursos para continuar con los programas sociales. Lo anterior puede entenderse como una alternativa económica, pero como se expuso antes, el extractivismo debe entenderse como un macrosistema, y para enfrentarlo se deben generar alternativas para cada uno de los sistemas que lo componen.

Frente a los sistemas social y ambiental, es necesario que se radicalicen las posturas. Por esto, el ecosocialismo propone una nueva sociedad centrada en una lógica ecológica y en la equidad social, priorizando el valor de uso sobre el valor de cambio, lo cual se presenta como una fuerte opción; de igual manera, es necesaria la colectivización de los bienes naturales y una verdadera soberanía sobre estos para que sea la sociedad quien decida qué hacer con ellos y cómo aprovecharlos. Con la intención de fortalecer esta lógica, la propuesta del giro ecoterritorial hecha por Maristella Svampa (2013) se vuelve cada vez más necesaria, la cual busca que sean las comunidades las que, alrededor de los bienes comunes que hay en su territorio, lo construyan y definan que hacer en él. Un ejemplo claro de esto es la propuesta de los Territorios Campesinos Agroalimentarios (CNA, 2015), propuesta campesina para organizar y proteger el territorio, centrada en la producción de alimentos, en la protección ambiental y en la organización comunitaria. Esta y otras propuestas se disputan el territorio con proyectos extractivos, compitiendo por agua, tierra y energía, lo cual dificulta la producción de alimentos, poniendo en riesgo la seguridad y soberanía alimentaria

10 Son los elementos que permiten generar energía por medio de diferentes procesos. 
del país, sin que eso desincentive por parte del Estado la explotación a gran escala de bienes naturales.

Ahora, frente al sistema político-institucional, tal vez lo más concreto sea seguir con las críticas fundamentadas al sistema político-económico extractivo y fortalecer los gobiernos locales y populares que buscan cuidar y blindar el territorio de actividades que lo pongan en riesgo.

Los puntos anteriores pueden entenderse como alternativas locales para cada país latinoamericano, pero como se ha dicho a lo largo del presente texto, este es un sistema de alcance mundial, por lo cual las opciones deben ser de esta envergadura. Quizá la primera acción deba ser criticar la concepción actual de desarrollo como crecimiento económico infinito, lo cual ha llevado a que el planeta esté a punto de superar sus límites, a cosificar a las personas y a calificarlas de acuerdo a su capacidad económica y de consumo, en un sistema que busca desarrollarse sin importar nada ni nadie.

El desarrollo es un mecanismo de poder y dominación, y así hay que entenderlo para enfrentarlo; para esto, se debe empezar desde cada persona. Es fundamental, entonces, que haya un cambio en el estilo de vida de las personas; es indispensable disminuir el consumo, sin dejar de atacar la producción.

Para cerrar este texto, creo relevante comentar que es inaudito pensar en que de un día para otro se lograrán cerrar todos los enclaves extractivos del planeta. El mudo necesita de cierto grado de extractivismo energético, lo que hay que definir es cuánto, para qué, quién o quiénes lo harán y cómo. Quizás, en el momento que esto sea resuelto, se le habrá ganado una fuerte lucha al capitalismo y al "desarrollo" que busca perseguir. 


\section{Acápite}

Durante el proceso de construcción de este documento, se logró la firma del acuerdo entre las Farc y el Gobierno colombiano, lo que para el sector extractivo significará un aumento en la disponibilidad de territorios para desarrollar proyectos de este tipo ante la "liberación" de zonas que durante años estuvieron vedadas por el conflicto armado. Lo anterior puede ser resumido en las palabras de Germán Arce, ministro de Minas y Energía:

El sector minero energético ha sido muy afectado por el conflicto. Las acciones terroristas han impactado de forma negativa la productividad y han puesto en riesgo los recursos con los que se financian los programas educativos, de infraestructura e inclusión social. Con la paz, aquellos territorios en conflicto y de difícil acceso serán lugares en donde los proyectos de hidrocarburos, minería y energía serán una realidad (Acosta, 2016).

Esto, seguramente, repercutirá en una mayor cantidad de conflictos socio-ambientales en el país.

\section{Referencias}

Acosta, Alberto (2012). Extractivismo y neoextractivismo: dos caras de la misma maldición. Recuperado de https://www.ecoportal.net/temas-especiales/ mineria/extractivismo_y_neoextractivismo_dos_caras_de_la_misma_maldicion/

Acosta, Javier (24 de agosto de 2016). Retos de la economía tras el acuerdo de paz. Portafolio. Recuperado de http://www.portafolio.co/economia/retosde-la-economia-colombiana-tras-el-acuerdo-de-paz-499846

ACNUR (2017). Base de datos.

Agencia Venezolana de Noticias (11 de abril 2016). El gobierno venezolano destina $71,4 \%$ del ingreso nacional a la inversión social. AVN. Recuperado de http://www.AVN.info.ve/contenido/gobierno-bolivariano-destina-714-delingreso-nacional-inversi \% C3\% B3n-social. 
Amnistía Internacional (17 de febrero de 2017). Perú: Nuevo ataque contra activista de la tierra Máxima Acuña, a dos días de visita internacional. Amnistía Internacional. Recuperado de https://www.amnesty.org/es/latest/ news/2017/02/peru-nuevo-ataque-contra-activista-de-la-tierra-maximaacuna-a-dos-dias-de-visita-internacional/.

Banco de la República (2015). Flujos de inversión extranjera directa en Colombia según actividad económica.

Carrizosa, Natalia (2 de julio de 2006). La polémica palma. Semana. Recuperado de http://www.semana.com/on-line/articulo/la-polemica-palma/772 72-3.

Cinep (2013). Impacto de la explotación minera en las mujeres rurales: afectaciones al derecho a la tierra y el territorio en el sur de La Guajira, Colombia. Recuperado de http://www.oidhaco.org/uploaded/content/article/2091974838.pdf

Comisión Nacional de Inversiones Extranjeras (2015). Informe estadistico sobre el comportamiento de la inversión extranjera directa en México.

Corporación para la Educación Popular, Instituto Nacional Sindical (Cedins) (2015, abril). Actividades de Anglogold Ashanti y Bloque Central Bolivar: ¿solo coincidencias?

De Chave, José (24 de Mayo de 2016). Súper ciclo y boom extractivo ies lo mismo? OCMAL Recuperado de https://www.ocmal.org/super-ciclo-y-boomextractivo-es-lo-mismo/

Díaz, Freddy (20 de abril 2015). Campesinos despojados de medios de vida. Desde Abajo. Recuperado de https://www.desdeabajo.info/ediciones/item /26282-campesinos-despojados-de-medios-de-vida.html.

Jiménez, Carlos Mario (27 de julio 2015). Aumentaron en $45 \%$ las enfermedades respiratorias por explotación de carbón. El Pilón. Recuperado de http://elpilon.com.co/aumentaron-en-45-las-enfermedades-respiratoriaspor-explotacion-de-carbon/

Escobar, Arturo (1986). La invención del desarrollo en Colombia. Lecturas de economía, 20, 9-35.

Garay, Ane (s.f). Inversión extranjera directa. ocmal. Recuperado de http:// omal.info/spip.php?article4822 
Garay, Luis Jorge (Dir.). (2013). Minería en Colombia: Derechos, políticas públicas y gobernanzas. Bogotá, Contraloría General de la Nación.

Grain (2009). Desenmascaremos algunos engaños sobre los monocultivos de árboles. Recuperado de https://www.grain.org/fr/article/entries/1222-desenmascaremos-algunos-enganos-sobre-los-monocultivos-de-arboles

Grupo de Memoria Histórica (2013). Informe ¡Basta Ya! Memorias de guerra y dignidad. Bogotá: Imprenta Nacional.

Gudynas, Eduardo (2009). Diez tesis urgentes sobre el nuevo extractivismo. Contextos y demandas bajo el progresismo sudamericano actual. En: Schuldt, Jürgen; Acosta, Alberto; Anthony, Barandiarán; Mauricio, Bebbington; Folchi, Mauricio; Gudynas, Eduardo et al. Extractivismo, política y sociedad. Quito, CAAP (Centro Andino de Acción Popular) y ClAEs (Centro Latino Americano de Ecología Social).

Human Rights Watch (2005). República Democrática del Congo-The Curse of Gold: Democratic Republic of Congo. Estados Unidos, HRW.

Infobae (5 de agosto de 2017). Pese al rechazo indígena, el gobierno de Bolivia quiere construir una carretera en una reserva ecológica. Infobae. Recuperado de https://www.infobae.com/america/america-latina/2017/08/05/ pese-al-rechazo-indigena-el-gobierno-de-bolivia-quiere-construir-una-carretera-en-una-reserva-ecologica/

Instituto Nacional de Estadística e Informática (INEI) (2016). Evolución de la pobreza monetaria 2009-2015.

Justicia Tributaria (2016). Guajira: Un modelo integralmente insostenible. Recuperado de http://justiciatributaria.co/guajira-un-modelo-integralmenteinsostenible/

Justo, Marcelo (9 de marzo 2016). ¿Cuáles son los 6 países más desiguales de América Latina? BBC Mundo.

Lander, Edgardo (2014). El neoextracctivismo como modelo de desarrollo en América Latina y sus consecuencias. Recuperado de https://Mx.boell.org/ sites/default/files/edgardolander.pdf

Machado, Horacio; Svampa, Maristella; Viale, Enrique; Giraud, Marcelo; Wagner, Lucrecia; Antonelli, Mirta; Giarracca, Norma, et al. (2012). 15 Mitos y realidad de la minería transnacional. Bogotá: Latino Impresores. 
OCDE (2014, marzo). Society at a glance 2014 highlights: Mexico oecd social indicators.

PAX (2014). El lado oscuro del carbón. La violencia paramilitar en la zona minera del Cesar, Colombia. Utrecht: Autor.

Petróleos de Venezuela S.A. (2014). Desarrollo Social. Balance de la gestión social y ambiental 2014.

PNUD (2015). Informe sobre desarrollo humano. Trabajo al servicio del desarrollo humano. Nota explicativa por país - Informe sobre desarrollo humano 2015. Nueva York, PNUD.

ProColombia (2015). Datos de la balanza cambiaria del Banco de la República.

Proinversión (2015). Saldo de inversión extranjera directa en el Perú como aporte al capital.

Quevedo, Norbey (14 de enero 2012). La petrolera Perenco y los “paras”. El Espectador. Recuperado de https://www.elespectador.com/noticias/investigacion/petrolera-perenco-y-los-paras-articulo-320929.

Redacción El Tiempo (10 de junio 2015). Prevén nueva caída en generación de empleo minero. El Tiempo. Recuperado de http://www.eltiempo.com/ archivo/documento/CMS-15928836.

Redacción Gestión (25 de abril 2016). ¿Por qué Cajamarca sigue siendo la región más pobre del país? Gestión. Recuperado de https://gestion.pe/economia/cajamarca-sigue-siendo-region-pobre-pais-118323.

Rudas, Guillermo (2012). La locomotora minera. ¿Crecimiento compatible con la adaptación al cambio climático? Recuperado de http://www.colombiapuntomedio.com/Portals/0/Economia/Miner \% C3 \% ADa \% 20y \% 20 Adaptaci \% C3\%B3n.pdf

Servindi (2016). Ecuador: Gobierno cierra ONG Acción Ecológica. Servindi. Recuperado de https://www.servindi.org/actualidad-noticias/21/12/2016/revanchismo-gobierno-ecuatoriano-cierra-ONG-accion-ecologica.

Tenthoff, Moritz (16 de febrero 2015). La explotación petrolera en el Centro Oriente y el oleoducto bicentenario de Colombia. Revista Semillas, 48/49. Recuperado de http://www.semillas.org.co/es/la-explotaci

Unicef México (2012). Pobreza y desigualdad. Recuperado de https://www. unicef.org/mexico/spanish/17046.html. 
